\title{
RELAÇÕES ISOTÓPICAS Rb-Sr E Sm-Nd E IDADES DO MAGMATISMO GRANÍTICO BRASILIANO DA REGIÃO LESTE DO CINTURÃO DOM FELICIANO NO RIO GRANDE DO SUL: EVIDÊNCIAS DE RETRABALHAMENTO DE CROSTA CONTINENTAL PALEOPROTEROZÓICA
}

\author{
JOSÉ CARLOS FRANTZ*, NILSON FRANCISQUINI BOTELHO**, MÁRCIO MARTINS PIMENTEL**, \\ ALAN POTREL**, EDINEI KOESTER* E ROBERTO SANTOS TEIXEIRA*
}

\begin{abstract}
R b$-Sr AND Sm-Nd ISOTPIC RELATIONS AND AGE OF THE BRASILIANO GRANITIC MAGMATISM OF THE EASTERN REGION OF THE DOM FELICIANO BELT IN THE RIO GRANDE DO SUL STATE: EVIDENCES OF REWORKING OF A PALAEOPROTE ROZOIC CONTINENTAL CRUST The granitoids belonging to the brasiliano cycle from the eastern region at the Dom feliciano Belt in the Rio Grande do Sul state have had $\mathrm{Rb}$-Sr data that indicated bodies which were intruded between 800 and 585Ma. The TDM ages are suggesting the participation of an older source in their generation. This source could be represented by a long period enriched mantle, much than would be expected during the evolution of the magmatic arcs, or could be represented by the interaction between an older continental crust and mantle during a continental collision regime. The tectonic evolution of this area, the existence of a long period of time between the granitic intrusions associated to the tangential regime and to the transpressive regime ones, the isotopic relations between $\mathrm{Sr}$ and $\mathrm{Nd}$ and the very low negative values of ENdt are suggesting a strong participation of an older continental crust. This older continental crust, may be constituted by gneissic protoliths of paleoproterozoic ages and generated during the evolution of the Transamazonic Cycle, has participated in the formation of the sources of the granitic magmatism of this part of the belt. The variations of the TDM ages and of the Nd ratios in the calc-alkaline granitoids are suggesting different proportions of mixture between an older continental crust and mantle or different homogenization grades in the magmas sources. For the peraluminous granites, that have be resulted from continental crustal melt, there are indications of different sources to the different bodies.

Keywords: Granitoids, Rb-Sr and Sm-Nd, Dom Feliciano Belt

RESUMO O presente trabalho trata dos granitóides brasilianos da região leste do Cinturão Dom Feliciano no Rio Grande do Sul. Os dados apresentados para o magmatismo, com relação às idades $\mathrm{Rb}-\mathrm{Sr}$ e às idades modelo $\mathrm{Sm}-\mathrm{Nd}$, indicam que as intrusões graníticas que se sucederam entre 800 e $585 \mathrm{Ma}$ foram geradas com a participação de uma fonte mais antiga. Esta fonte pode representar um manto enriquecido por um período superior ao que seria esperado na evolução de arcos magmáticos ou representar uma forte participação de crosta continental mais antiga na gênese desse magmatismo, iniciado durante um regime de colisão continental. A evolução tectônica da área, o longo período de tempo observado entre as manifestações graníticas associadas a um regime tangencial e as associadas a um regime transcorrente, as relações entre isótopos de Sr e de $\mathrm{Nd}$ e os valores negativos de $\varepsilon_{\mathrm{Ndt}}$ sugerem uma forte participação de crosta mais antiga. Essa crosta, possivelmente constituída por protólitos gnáissicos de idade paleoproterozóica gerada durante o Ciclo Trasamazônico, participou da constituição das fontes do magmatismo granítico dessa parte do cinturão. As variações observadas nas idades modelo, nos valores negativos de $\varepsilon_{\mathrm{Ndt}}$ e nas razões de $\mathrm{Nd}$, nos granitóides cálcio-alcalinos, sugerem diferentes proporções para essa participação de crosta continental mais antiga ou, ainda, diferentes graus de homogeneização nas fontes desses magmas. Nos granitóides peraluminosos resultantes da fusão de crosta continental há indicações de fontes diferentes para os vários corpos trabalhados.
\end{abstract}

Palavras-chave: Granitóides, Rb-Sr e Sm-Nd, Cinturões Dom Feliciano

INTRODUÇÃO O Escudo Sul-rio-grandense integra, em sua maior parte, o Cinturão Dom Feliciano (Fragoso-Cesar 1980), com as principais associações de rochas indicando uma geração e estruturação controladas pela evolução do Ciclo Brasiliano.

Os poucos registros de associações de idades paleoproterozóicas ocorrem como fragmentos de crosta mais antiga, que foram preservados durante o desenvolvimento desse cinturão (Fig. 1). Na região oeste do Escudo, estão representados por ortognaisses granulíticos em Dom Pedrito (Nardi \& Hartmann 1979) e por rochas máfíco-ultramáficas em Palma e Mata Grande (Issler et al. 1967). Na região leste, as associações pré-brasilianas preservadas em escala mapeável estão restritas à infraestrutura do Domo de Santana (Jost 1981), possivelmente aos metanortositos e aos paragnaisses de Capivarita (Frantz et ai. 1984) e aos paragnaisses de Toninhas (Frantz e Remus 1986). No entanto, na região leste, inúmeros registros podem ser associados a rochas gnáissicas que ocorrem como xenólitos, de escala métrica a centimétrica, no interior de granitóides cálcio-alcalinos precoces na evolução do cinturão.

As associações transamazônicas da região oeste têm sido interpretadas como integrantes do Cráton do Rio de La Plata (Almeida et al 1973, Hasui et al. 1975, Fragoso-Cesar 1980), assim denominado por sua melhor representação no Escudo Uruguaio. Na região leste, essas associações podem ser melhor entendidas como descolamentos crustais do embasamento, desenvolvidos durante a atuação de uma fase tectônica tangencial que marcou o início da estruturação do Cinturão Dom Feliciano.

A região leste do cinturão pode ser subdividida em duas faixas principais. Uma, mais ocidental, é constituída por rochas supracrustais do Complexo Cerro da Árvore, que integra a Suíte Metamórfíca Porongos (Jost 1981). Outra, mais oriental, é constituída por batólitos graníticos, em alguns casos poli-diapíricos, cujas injeções sucessivas foram controladas pela atividade tectônica do cinturão segundo sua evolução cinemática (Frantz e Remus 1986).
A evolução cinemática indica a atuação de uma tectônica tangencial e outra transcorrente para o cinturão, de acordo com os dados existentes para a região leste (Jost 1981, Frantz et al. 1984, Jost et al. 1984, Fernandes et al. 1990). Para a região oeste inexistem trabalhos sistemáticos com o objetivo de definir a evolução cinemática do cinturão e correlacioná-la à evolução do magmatismo presente.

O regime tangencial foi responsável pela geração de imbricações tectônicas, espessamento crustal resultante de nappes de caval-

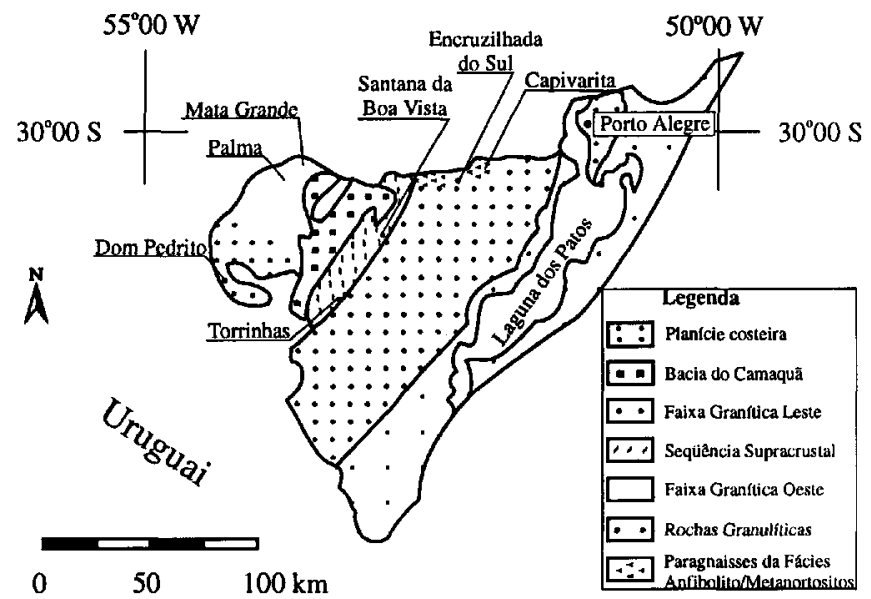

Figura l - Esboço das regiões leste e oeste do cinturão Dom Feliciano com as principais associações litológicas que constituem o Escudo Sul-rio-grandense.

* Instituto de Geociências, Universidade Federal do Rio Grande do Sul, Campus do Vale, Av. Bento Gonçalves 9500, CEP 91540-000, Porto Alegre, RS, e-mail: frantz@if.ufrgs.br, ekoester@vortex.ufrgs.br

** Instituto de Geociências, Universidade de Brasília, Campus Asa Norte, CEP 70910-900, Brasília, DF, e-mail: nilsonfb@unb.br, mareio@unb.br, potrel@unb.br 
gamento, transporte tectônico de parte de algumas unidades, como ocorreu com o Complexo Cerro da Árvore (Jost 1981). Durante este regime ocorreu a estruturação de algumas das associações de rochas supracrustais da Suíte Metamórfica Porongos e a injeção dos granitóides cálcio-alcalinos sin-tangenciais (Frantz e Remus 1986), que representam o principal marcador geológico da fase tectônica tangencial.

A tectônica transcorrente (Frantz et al. 1984) foi responsável por deslocamentos longitudinais de grande porte ao longo do cinturão (Jost et al. 1984), atuando em regime transpressivo (Fernandes et al. 1990). Foi, ainda, o principal mecanismo controlador das injeções de magmas graníticos cálcio-alcalinos e de fusão crustal, bem como de magmas básicos representados por uma série de diques sin-cinemáticos de diabásio (Frantz e Remus 1986).

A passagem do regime transpressivo a trativo ao final do Ciclo Brasiliano permitiu que as faixas de cisalhamento, desenvolvidas durante a transcorrência, atuassem como os principais condutos que alojaram as intrusões graníticas pós-orogênicas - do Cinturão Dom Feliciano (Frantz e Fernandes 1994). As intrusões pós-orogênicas do cinturão correspondem a fases de intrusões pós-tectônicas ao cisalhamento transcorrente.

IDADES Rb-Sr DO MAGMATISMO GRANÍTICO O comportamento isotópico para $\mathrm{Rb}$-Sr nos granitóides cálcio-alcalinos da fase tectônica tangencial independe do sistema ter sido aberto ou não durante a deformação. Isto pode ser considerado em virtude das características estruturais e texturais das rochas selecionadas indicarem idades similares para o posicionamento, para o início do magmatismo granítico sin-tangencial e para o pico da deformação associada a esse regime tectônico.

O diagrama isocrônico para essa fase tectônica e de magmatismo granítico foi obtido com 12 pontos, indicando uma idade de $800 \pm 32 \mathrm{Ma}$ e razão inicial ${ }^{87} \mathrm{Sr} / \mathrm{Sr}^{87}$ de 0,7050 . Essa idade representa o início do magmatismo granítico cálcio-alcalino na região leste do Cinturão Dom Feliciano e o período de deformação tangencial mais intensa na área (Fig. 2).

As idades das injeções graníticas relacionadas à fase de deformação transcorrente estão definidas a partir dos dados produzidos por Koester et al. (1994) tanto para os granitóides cálcio-alcalinos quanto para os granitóides de fusão crustal da Suíte Intrusiva Cordilheira (Frantz e Nardi 1992a). Nesse aspecto, tais dados fornecem uma avaliação bastante coerente para a evolução temporal do magmatismo granítico e para a evolução temporal da própria deformação transcorrente.

O magmatismo granítico cálcio-alcalino da fase tectônica transcorrente teve início com o posicionamento de um corpo porfirítico de composição granodiorítica, definido como gnaisse Maria Santa (Frantz et al. 1984) ou metagranito Quitéria (Fernandes et al. 1990), na porção nordeste do cinturão. Mostra características estruturais compatíveis com as de intrusões ocorridas durante períodos de deformação mais intensa em regime transcorrente e foi datado por Koester et al. (1994) em 672 $\pm 22 \mathrm{Ma}$ com $\mathrm{R}_{0}$ de 0,716 .

As intrusões sucessivas de corpos de leucogranitos de fusão crustal da Suíte Intrusiva Cordilheira marcam períodos de progressiva atenuação da deformação gerada pela transcorrência. Assim, os primeiros corpos de biotita-muscovita granitos desta suíte, posi-

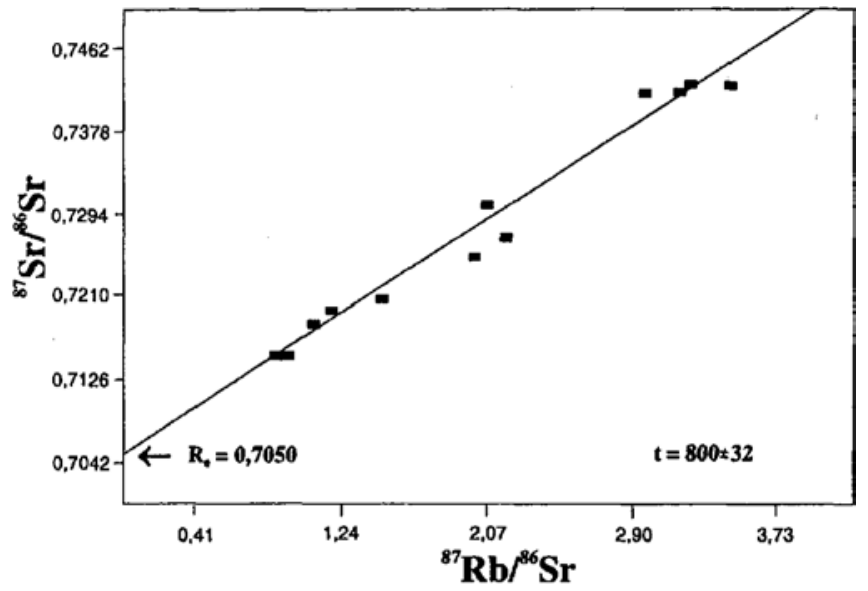

Figura 2 - Diagrama isocrônico $\mathrm{Rb}-\mathrm{Sr}$ de granitóide cálcio-alcalino sin-cinemático à tectônica tangencial e que marca o início do magmatismo associado ao periodo de colisão continental no Cinturão Dom Feliciano. cionados ao longo das faixas miloníticas, marcam o início da injeção de corpos graníticos peraluminosos durante a transeorrência. A isócrona obtida por Koester et al. (1994) para um corpo granítico desta fase de injeção, Granito Arroio Francisquinho, indica uma idade de $630 \pm 22 \mathrm{Ma}$ com RO de 0,732 . Os muscovita ( \pm turmalina \pm granada) granitos, mais diferenciados e menos deformados que os anteriores, foram posicionados durante os estágios finais da deformação gerada pela transcorrência. Têm sua idade representativa no Granito Cordilheira em $617 \pm 48 \mathrm{Ma}$ com Ro de 0,741 (Koester et al. 1994). Considerando o erro bastante grande, torna-se arriscado estabelecer uma idade para o final da deformação transcorrente e para o fim do magmatismo peraluminoso que a acompanhou.

Uma estimativa, no entanto, pode ser feita a partir das idades existentes para os granitóides cálcio-alcalinos tardi a pós-tectônicos, situadas ao redor dos $600 \mathrm{Ma}$, como ocorre com os da Suíte Intrusiva Campinas. A partir desta idade, todos os corpos graníticos da região leste do Cinturão Dom Feliciano mostram características de injeções ocorridas sob regime trativo, com a deformação sendo representada por cataclase desenvolvida durante reativações extensivas das faixas miloníticas geradas pela transcorrência.

Os registros geocronológicos para a região leste do Cinturão Dom Feliciano são raros para essa fase de geração de rochas granitóides, estando restritos a uma idade de referência obtida por Soliani Júnior (1986) de $570 \pm 13 \mathrm{Ma}$ para a Suíte Intrusiva Encruzilhada (Frantz e Fernandes 1994). Os granitóides cálcio-alcalinos pós-orogênicos não foram objeto de detalhamento por terem sido, muitas vezes, interpretados como parte do magmatismo alcalino-metaluminoso da Suíte Intrusiva Encruzilhada. A composição petrográfica muito evoluída, com domínio de termos sienograníticos, e o controle de posicionamento dos corpos já indicando a atuação de uma tectônica trativa, permitem separar corpos isolados apenas através de dados petrológicos, como é o caso do Granito Canguçu.

O Granito Canguçu representa um dos pulsos finais do magmatismo cálcio-alcalino na região leste. Seu controle tectônico é definido por reativações extensivas de faixas de milonitos gerados na transcorrência, com brechação em zonas de contato, eventuais margens resfriadas e cavidades miarolíticas, indicando posicionamento epizonal. O diagrama isocrônico para esse granito, com 12 amostras, indicou uma idade de $585 \pm 13 \mathrm{Ma}$ e RO de 0,7082 (Fig. 3).

A idade do Granito Canguçu indica não apenas o final do magmatismo cálcio-alcalino no Cinturão Dom Feliciano, mas assinala também a mudança do regime tectônico para francamente trativo como controlador da evolução final do cinturão e do seu magmatismo. De qualquer forma, é possível considerar uma idade relativa em torno de 570 a $550 \mathrm{Ma}$ como referência para o final do magmatismo granítico do cinturão. Nesse caso, um magmatismo já francamente alcalino, representado pela Suíte Intrusiva Encruzilhada e corpos graníticos isolados.

DADOS DE ISÓTOPOS Nd-Sm Granitóides cálcio-alcalinos sin-tangenciais A participação de crosta continental na geração do magmatismo cálcio-alcalino alto $\mathrm{K}$ da faixa leste do Cinturão Dom Feliciano já foi estabelecida através das relações composicionais e geoquímicas observadas para estas rochas (Frantz e Nardi 1992b) e fica mais evidente diante das relações isotópicas existentes para os granitóides da região. Os valores negativos de $\varepsilon_{\mathrm{Ndt}}$, situados

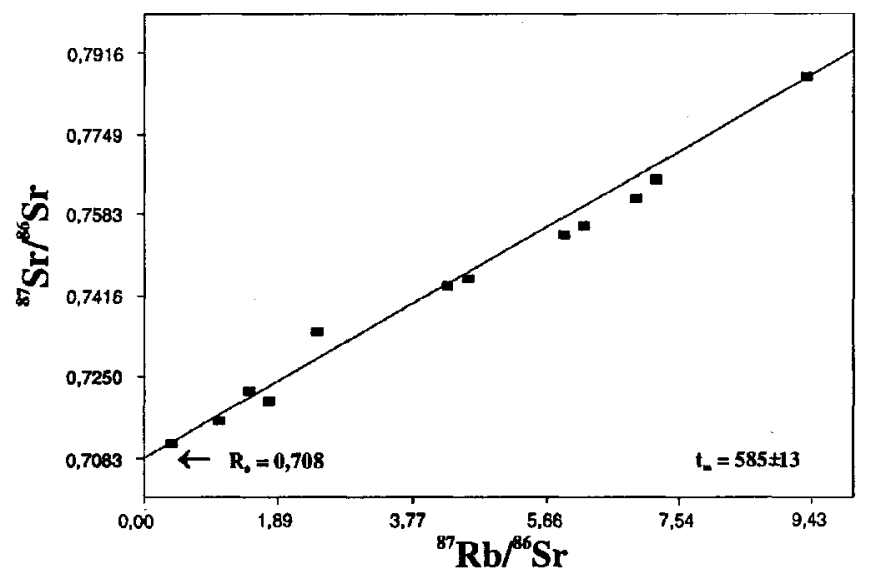

Figura 3 - Diagrama isocrônico $\mathrm{Rb}-\mathrm{Sr}$ de granitóide pós-cinemático à tectônica transcorrente indicando o final do magmatismo cálcio-alcalino associado à evolução do Cinturão Dom Feliciano. 


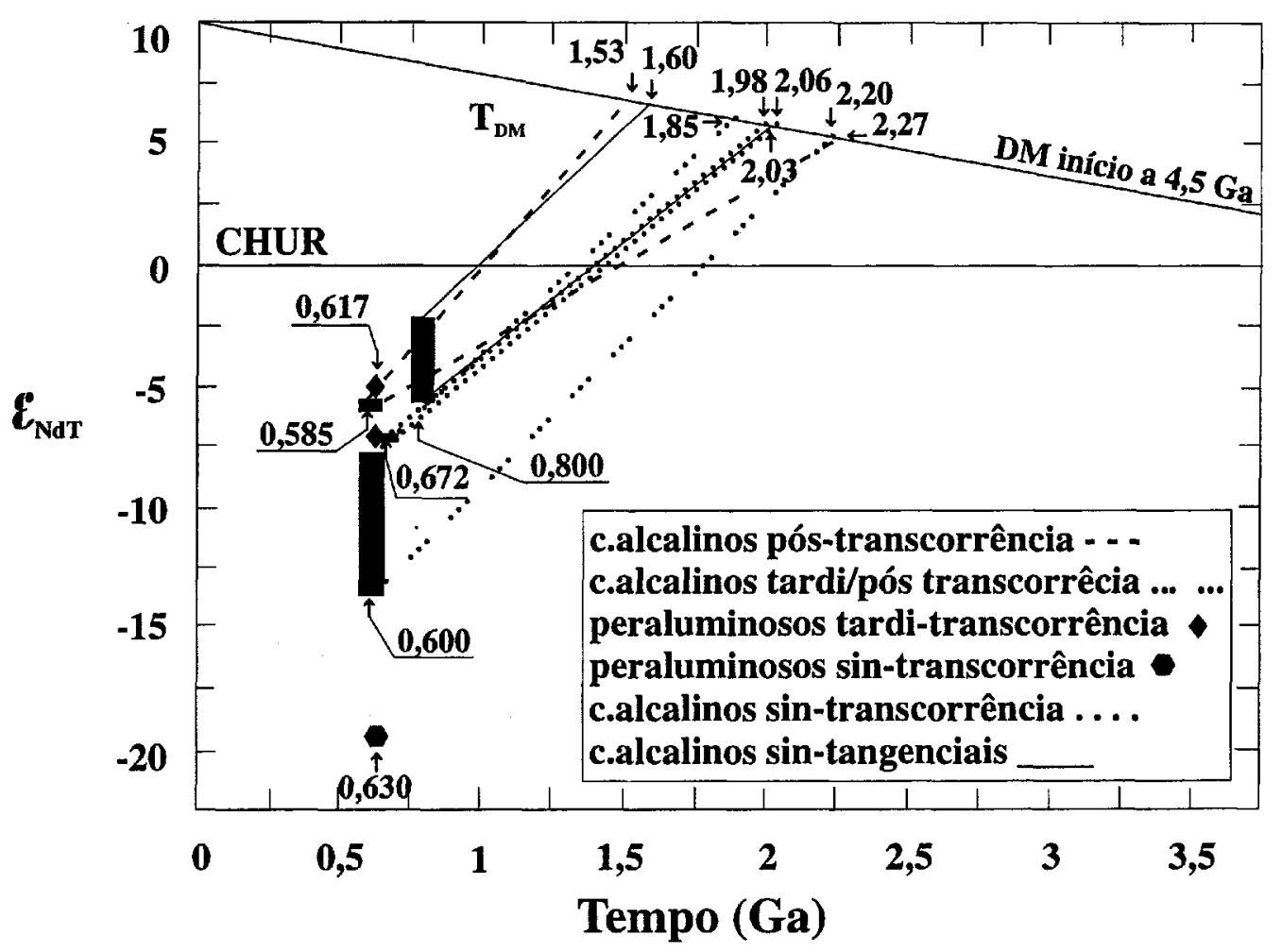

Figura 4 - Diagrama $\varepsilon_{N d T} x$ tempo (Rb-Sr) mostra idades modelo entre 2,27 e l,53Ga com valores de $\varepsilon_{\text {NdT }}$ negativos para os granitóides cálcio-alcalinos de todas as fases tectônicas da região leste do Cinturão Dom Feliciano, indicando participação de crosta continental e ausência de magmas juvenis na geração desse magmatismo granítico. Os granitóides peraluminosos têm relações características de rochas geradas por fusão de crosta continental.

entre $-2,1$ e $-6,0$ e a grande diferença observada para as idades modelo, situadas entre 1,6 e $2,03 \mathrm{Ga}$ e as razões iniciais ${ }^{87} \mathrm{Sr} /{ }^{86} \mathrm{Sr}$ elevadas das associações, sugerem a ausência de processos de formação de crosta juvenil na origem destas rochas (Fig.4). Ao contrário, sugerem retrabalhamento crustal, com o magmatismo granítico resultando de uma fonte com forte participação de crosta continental mais antiga.A variação bastante ampla dos valores de $\varepsilon_{\mathrm{Ndt}}$ observada para os granitóides sin-tangenciais representa, possivelmente, um menor grau de homogeneização na fonte destas rochas.

A relacão entre as razões ${ }^{143} \mathrm{Nd} /{ }^{144} \mathrm{Nd}$ situadas entre 0,5119 e $0,5121 \mathrm{e}^{87} \mathrm{Sr}{ }^{86} \mathrm{Sr}$ reforça o envolvimento de um component crustal. Este envolvimento pode ter ocorrido tanto na forma de um agente responsável por enriquecimentos mantélicos quanto na forma de material com envolvimento direto na fonte do magmatismo, possivelmente como parte de mistura com material de derivação mantélica. Os valores observados para ambas as razões isotópicas são compatíveis com sistemas magmáticos resultantes de uma fonte que apresentou forte participação de material originário de crosta continental em mistura com material derivado do manto (Fig.5).

\section{Granitóides cálcio-alcalinos sin a tardi-transcorrência}

O magmatismo granítico cálcio-alcalino dessa fase tectônica é representado por corpos isolados e alongados segundo a direção do Cinturão. Corpos graníticos com características estruturais compatíveis com as de intrusões ocorridas durante períodos de deformação mais intensa em regime transcorrente representam o início do magmatismo em $672 \pm 22 \mathrm{Ma}$ com RO de 0,716 (Koester et al 1994).

Esses granitóides têm idades modelo situadas entre 1,98 e 2,06Ga para valores de £Ndt variando entre -7,2 e -7,4 (Fig. 4). As razões ${ }^{143} \mathrm{Nd} /{ }^{144} \mathrm{Nd}$ estão situadas em torno de 0,5119 para uma razão inicial ${ }^{87} \mathrm{Sr} /{ }^{86} \mathrm{Sr}$ bastante alta para granitóides cálcio-alcalinos (Fig. 5). Tais relações indicam o envolvimento e uma forte participação de componentes crustais na gênese dos granitóides cálcio-alcalinos precoces do regime tectônico transcorrente. No entanto, com um maior grau de homogeneização na fonte dos mesmos em comparação aos dados obtidos para os granitóides cálcio-alcalinos da fase tectônica sintangencial.

Granitóides peraluminosos sin a tardi-transcorrência Os dados isotópicos $\mathrm{Sm}-\mathrm{Nd}$ e $\mathrm{Rb}-\mathrm{Sr}$ indicam que os granitóides peralu- minosos da Suíte Intrusiva Cordilheira foram derivados a partir da fusão de crosta continental preexistente. Os valores de $\mathrm{e}_{\mathrm{Ndt}}$ negativos variando de $-5,4$ a $-19,3$ sugerem que, ao menos para os dois corpos considerados e que representam injeções sin e tardi-transcorrência, há uma grande possibilidade de representarem fontes crustais com características diferentes (Fig. 4). As razões ${ }^{143} \mathrm{Nd} /{ }^{144} \mathrm{Nd}$, situadas entre 0,5120 e $0,5123, e^{87} \mathrm{Sr}{ }^{86} \mathrm{Sr}$ indicam variações amplas entre os dois corpos, e inclusive para o corpo tardi-transcorrência, o que sugere uma origem a partir de fontes crustais com diferentes composições isotópicas (Fig. 5).

Granitóides cálcio-alcalinos tardi a pós-transcorrência O padrão isotópico obtido para as rochas graníticas da Suíte Intrusiva Campinas indica, assim como os demais dados disponíveis, a existência de um intervalo bastante amplo para os valores de $\varepsilon_{\text {Ndt }}$ o que é compatível com a participação de material mais antigo de origem crustal. A participação de crosta continental fica evidente diante das relações texturais destas rochas, como a grande incorporação de xenólitos parcialmente assimilados em seu interior, e das relações isotópicas existentes para os granitóides da suíte. Os valores negativos de $\varepsilon_{\text {Ndt }}$, entre $-8,4 \mathrm{e}-13,2$ ea grande diferença observada nas idades modelo, situadas entre 1,85 e 2,20Ga, e a idade Rb-Sr das associações, sugerem a ausência de processos de geração de magmas juvenis na origem destas rochas (Fig. 4). Ao contrário, há uma forte indicação de retrabalhamento crustal, com o magmatismo granítico sendo resultante da assimilação de crosta continental mais antiga em um processo de interação com material que pode ter sido originário do manto. A variação ampla dos valores de $\varepsilon_{\mathrm{Ndt}}$, observada para os granitóides da Suíte Intrusiva Campinas, além de representar possíveis heterogeneidades na fonte destas rochas (Zhao e McCulloch 1996) pode estar representando os diferentes graus de mistura entre material cristalizado do magma original e material crustal mais antigo (Moreno-Ventas et al. 1995) através da incorporação e assimilação de microxenólitos.

A relação existente entre ${ }^{143} \mathrm{Nd} /{ }^{144} \mathrm{Nd}$, com valores variando de 0,5116 a 0,5119 , e a razão inicial ${ }^{87} \mathrm{Sr}{ }^{86} \mathrm{Sr}$ de 0,7154 parece reforçaro forte envolvimento de um componente crustal (Fig. 5). Os valores observados para ambas as razões isotópicas são compatíveis com sistemas magmáticos resultantes de mistura, onde o principal componente 


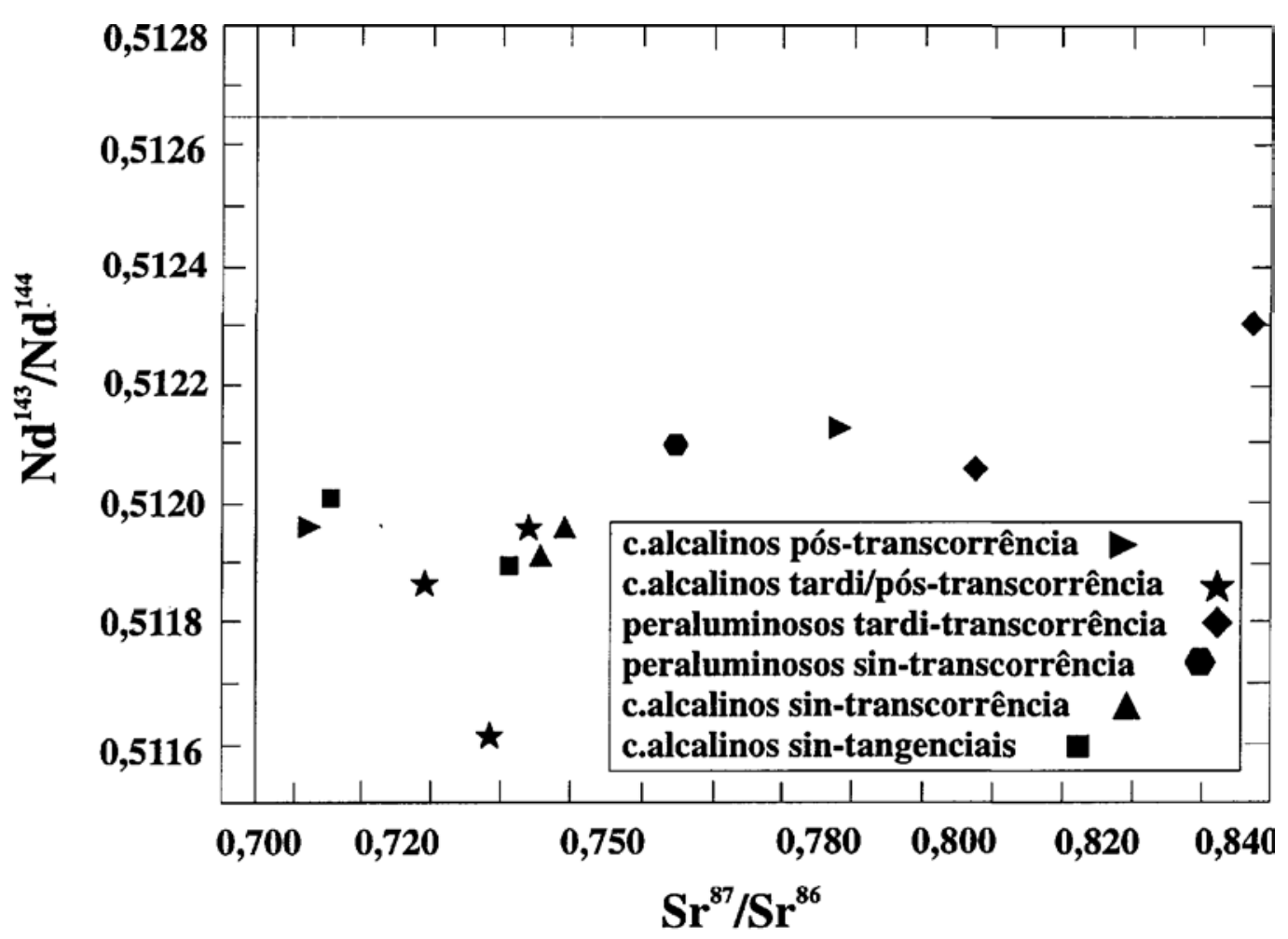

Figura 5 - Diagrama ${ }^{143} \mathrm{Nd} /{ }^{144} \mathrm{Nd} x{ }^{87} \mathrm{Sr}{ }^{86} \mathrm{Sr}$, com as razões indicando forte participação de crosta continental em diferentes graus de hibridização com um possível componente mantélico na geração dos granitóides cálcio-alcalinos associados a todas as fases tectônicas durante evolução da região leste do Cinturão Dom Feliciano. Essas razões indicam fontes crustais com diferentes composições isotópicas envolvidas na geração dos granitóides peraluminosos relacionados à transcorrência.

é originário de crosta continental com o possível envolvimento de um componente derivado do manto.

Granitóides cálcio-alcalinos pós-transcorrência O Granito Canguçu, de forma semelhante aos demais granitóides cálcio-alcalinos alto K da região leste do Cinturão Dom Feliciano apresenta evidências de participação de crosta continental na sua geração. Isto fica claro diante das relacões isotópicas existentes, como os valores negativos de $\varepsilon_{\text {Ndt }}$ entre $-5,8$ e $-6,1$ e a grande diferença observada entre as idades modelo, entre 1,53 e $2,27 \mathrm{Ga}$, e as idades isocrônicas $\mathrm{Rb}-\mathrm{Sr}$, que sugerem que o magmatismo granítico resultou de um processo que envolveu uma forte e heterogênea interação com crosta continental mais antiga (Fig. 4).

A relação existente entre ${ }^{143} \mathrm{Nd} /{ }^{144} \mathrm{Nd}$, com valores entre 0,5119 e 0,5121 , e $\mathrm{Sr} / \mathrm{Sr}$ reforça a possibilidade de que tenha havido o envolvimento de um componente derivado de crosta continental como agente de enriquecimento mantélico ou que tenha ocorrido um simples retrabalhamento crustal (Fig. 5). Os valores observados para ambas as razões isotópicas são compatíveis, ainda, com sistemas magmáticos resultantes de mistura entre componentes de origem diversa, mantélica entre estas, com acentuada participação de material de derivação crustal.

EVOLUÇÃO DO SISTEMA GRANÍTICO Os granitóides cálcio-alcalinos, gerados durante a deformação tangencial, têm composiç̃es com amplo predomínio de termos granodioríticos. Estes, apresentam grande quantidade de xenólitos de anfibolitos (anfibólio + plagioclásio) e paragnaisses (silimanita \pm espinélio \pm granada \pm K-feldspato ou diopsídio \pm anfibólio \pm plagioclásio \pm quartzo), e de autólitos dioríticos. Os xenólitos anfibolíticos têm idades de $884 \pm 19 \mathrm{Ma}$ com razão inicial ${ }^{87} \mathrm{Sr}{ }^{86} \mathrm{Sr}$ de 0,7027 (Soliani Júnior 1986), o que sugere uma origem mantélica para estas rochas. Os paragnaisses associados, que representam um componente crustal, fazem parte, juntamente com os anfibolitos, de um conjunto de rochas cuja gênese esteve ligada a processos geológicos que precederam a geração dos granitóides sintangenciais.

A associacão das rochas graníticas da fase sin-tangencial, com grande quantidade de xenólitos gnáissicos de natureza paraderivada e composições aluminosas e cálcio-silicáticas, indicando paragêneses de grau alto de metamorfismo, já foi descrita anteriormente (Frantz e Remus 1986). Esta associação, junto com as características estruturais e litoquímicas e o fato do magmatismo ser cálcio-alcalino alto potássio desde o início (Frantz e Nardi 1992b), sugerem que a geração e a evolução do sistema granítico durante o Ciclo Brasiliano na região leste do Cinturão Dom Feliciano estiveram diretamente ligadas a presença de crosta continental espessa em um regime de colisão continental (Worku e Schandelmeier 1996). Nessa condição, o início do magmatismo granítico cálcio-alcalino alto $\mathrm{K}$ sin-tangencial representa também o início da fase de colisão continental e, como conseqüência, o início da consolidação do Cinturão Dom Feliciano.

A evolução temporal do magmatismo granítico cálcio-alcalino alto $\mathrm{K}$ indica que o mesmo teve posicionamento sin-cinemático para a maior parte dos batólitos durante a fase tectônica tangencial. A idade $\mathrm{Rb}$-Sr obtida para este evento magmático, de $800 \pm 32$ Ma e razão inicial de 0,705 , representa, assim, o evento de colisão continental que foi responsável pelo início do magmatismo granítico, possivelmente sem a geração anterior de um arco magmático, devido a não identificação, até o momento, de rochas plutônicas e vulcânicas que caracterizem uma associação deste tipo.

A seqüência de eventos graníticos indica que as manifestações do magmatismo pós-colisional teve seu início com o desenvolvimento de uma fase de deformação transpressiva que afetou a região leste muito após a colisão e colagem continental. Os granitóides cálcio-alcalinos alto $\mathrm{K}$, posicionados em regime sin a tardi-cinemático, apontam para o Granito Quitéria a idade de $672 \pm 22 \mathrm{Ma}$, com $\mathrm{R}_{0}$ de 0,716 (Koester et al. 1994). Esta idade define o início do magmatismo e da deformação associada à transcorrência. As idades de $630 \pm 22 \mathrm{Ma}$, com razão inicial de 0,732 , e de $617 \pm 48 \mathrm{Ma}$, com RO de 0,741 (Koester et al. 1994) definem, ainda que com margem de erro elevada, o período de tempo em que ocorreram as injeções sin a tardi-cinemáticas do magmatismo granítico peraluminosos de fusão crustal da Suíte Intrusiva Cordilheira.

A evolução da faixa leste do Cinturão Dom Feliciano tem seqüência com a injeção de corpos graníticos como os da Suíte Intrusiva Campinas, em estágios tardi a pós-transcorrência, e é encerrada com as últimas manifestações graníticas da região em um regime francamente extensivo. Este regime extensivo é indicado pelo posicionamento das 
injeções cálcio-alcalinas alto K pós-tectônicas da Suíte Intrusiva Canguçu, com o Granito Canguçu apresentando uma idade $\mathrm{Rb}-\mathrm{Sr}$ de $585 \pm 13$ Ma e razão inicial de 0,708. As manifestações finais do magmatismo granítico do cinturão estão representadas por intrusões alcalino-metaluminosas da Suíte Intrusiva Encruzillhada e corpos isolados peralcalinos. A estruturação final do Cinturão Dom Feliciano tem lugar, assim, com injeções graníticas muito evoluídas em um regime tectônico francamente extensivo.

CONCLUSÕES A elevação nas razões iniciais ${ }^{87} \mathrm{Sr} /{ }^{86} \mathrm{Sr}$, como observado em todos os granitóides da região leste do Cinturão Dom Feliciano, pode ser causada por presença de uma litosfera subcontinental que tenha sido afetada por metassomatismo por períodos mais longos do que ocorreria em arcos de ilhas clássicos (Saunders et al. 1991). No entanto, essas razões, também podem refletir magmas cuja fonte apresentou o envolvimento de crosta continental, o que é sugerido por valores negativos de $\varepsilon_{\mathrm{Ndt}}$, com a geração de protólitos ígneos de composição relativamente homogênea e que resultam de uma fase de colisão continental (Tommasini et al. 1995).

A colisão continental e o magmatismo granítico associado representam a $800 \mathrm{Ma}$, possivelmente, os estágios finais de evolução de uma bacia do tipo plataforma (Suíte Metamórfica Porongos de Jost 1981), ou margem passiva, submetida a um evento compressivo que pode ter levado a uma subducção intracontinental ou subducção do tipo A (Bally 1981, Jacobshagen 1994).

As associações de rochas supracrustais, até o momento, não foram objeto de detalhamento geocronológico. No entanto, rochas anfibolíticas derivadas do magmatismo básico intercalado foram definidas através de isócrona $\mathrm{Rb}-\mathrm{Sr}$ como tendo $884 \pm 19$ Ma com razão inicial 0,702 (Soliani Júnior 1986). Portanto, muito anteriores a geração do magmatismo granítico e ligadas a um ambiente tectônico, possivelmente extensivo, acompanhado por ampla sedimentação.

$\mathrm{O}$ vulcanismo dacítico-riolítico cálcio-alcalino alto $\mathrm{K}$ do Complexo Cerro da Árvore (Jost 1981), embora sem referências geocronológicas, pode ser correlacionado ao tempo de evolução do magmatismo granítico da região leste em função de seu quimismo e da relação tectônica com a fase de deformação tangencial. Nesta condição deve estar representando um evento magmático posterior à sedimentação de plataforma passiva que gerou os espessos pacotes de quartzitos, metapelitos e mármores da Suíte Metamórfica Porongos (Jost 1981).

O magmatismo granítico desenvolvido durante uma fase de deformação transpressiva que afetou a região leste muito após a colisão e colagem continental é compatível com sistemas graníticos associados a crosta continental espessa, ou intracontinentais. Os granitóides cálcio-alcalinos alto $\mathrm{K}$, posicionados em regime sin a tardi-cinemático, apontam para o início deste magmatismo a partir de $672 \pm 22 \mathrm{Ma}$
(Koester et al. 1994) com razões iniciais ${ }^{87} \mathrm{Sr} /{ }^{86} \mathrm{Sr}$ elevadas e em acordo com sistemas graníticos gerados sob a participação de crosta continental. Essa idade representa, também, o início da deformação associada à transcorrência.

As idades entre 600 e $585 \mathrm{Ma}$, respectivamente representadas pela Suíte Intrusiva Campinas e Granito Canguçu, marcam o final do regime tectônico transcorrente e o início de um regime francamente extensivo na região leste do Cinturão Dom Feliciano, com as últimas manifestações do magmatismo granítico cálcio-alcalino.

Os valores de $\varepsilon_{\mathrm{Ndt}}$ sempre inferiores a -2 e média abaixo de -5 indicam a sistemática participação de crosta continental na geração de todos os granitóides cálcio-alcalinos analisados, desde a fase tectônica tangencial até os corpos pós-cinemáticos à transcorrência. A relação existente entre ${ }^{143} \mathrm{Nd} /{ }^{144} \mathrm{Nd}$, com valores entre 0,5116 e 0,5123 , as razões iniciais ${ }^{87} \mathrm{Sr}{ }^{86} \mathrm{Sr}$, com valores sempre acima de 0,706 reforça o forte envolvimento de crosta continental como um componente importante na composição das fontes envolvidas na gênese dos magmas. Essa participação de crosta pode ter ocorrido tanto como agente de enriquecimento mantélico quanto como parte da fonte envolvida na gênese dos sistemas graníticos através de retrabalhamento crustal. Os valores observados para ambas as razões isotópicas são compatíveis com sistemas magmáticos resultantes de mistura em proporções diversas entre material originário de crosta continental com material de derivação mantélica (Serri et al. 1993, Tommasini et al. 1995, Turner et al. 1996).

As idades modelo $\mathrm{Sm}-\mathrm{Nd}$ oscilando num intervalo amplo de valores entre 1,53 e $2,27 \mathrm{Ga}$ e a grande diferença observada com relação a idades convencionais $\mathrm{Rb}$-Sr sugerem que o magmatismo granítico resultou de fontes que contaram com a forte participação de crosta continental mais antiga (Brandon e Lambert 1994, Innocent et al. 1994, Sun et al. 1995), possivelmente paleoproterozóica, em uma provável interação com material proveniente do manto. Nesse sentido, são favorecidas as rochas gnáissicas quartzo-feldspáticas geradas durante o Ciclo Transamazônico, que afloram em várias porções do cinturão, como um dos possíveis componentes das fontes para o magmatismo granítico cálcio-alcalino brasiliano do Cinturão Dom Feliciano.

As diferenças observadas nas idades modelo e suas variações em intervalos de maior ou menor amplitude seriam resultantes de proporções variadas de mistura entre os componentes das fontes ou, ainda, dos diversos graus de homogeneização nas fontes desse magmatismo (Zhao e McCulloch 1996).

Agradecimentos Aos relatores anônimos por suas sugestões ao manuscrito.

\section{Referências}

Almeida, F f.M.; Amaral, G.; Cordani, U.G.; Kawashita, K. 1973. The Precambrian evolution of the South American Craton. In: A.E. Nairn e F.G. Stehli (eds.) The Ocean Basin and Margins. New York, Plenum, 1411-1446.

Bally, A. W. 1981. Thoughts on the tectonics of folded belts. In: K. R. McClay e N. J. Price (eds.) Thrust and Nappe Tectonics. Londres, Spec. Publ. Geol. S. London 9,13-32.

Brandon, A.D. e Lambert, R. 1994. Crustal melting in the Cordilleran Interior: The mid-cretaceous White Creek Batholith in the Southern Canada Cordillera. /. Petrol. 35(1): 239-269.

Fernandes, L.A.D.; Tommasi, A.; Porcher, C.C. 1990. Esboço Estrutural de Parte do Batólito Pelotas -Região de Quitéria-Capivarita. Estudos Tecnológicos, v. XIII. Acto Geol. Leopold., 30: 117-138.

Fragoso-Cesar, A.R. 1980. O Craton do Rio da la Plata e o Cinturão Dom Feliciano no Escudo Uruguaio-Sul-Riograndense. In: S.B.G., Cong. Bras. Geol., 31, Camboriú, Anais, 5:2879-2891.

Frantz, J.C. e Fernandes, L.A.D. 1994. Os Granitóides Tardi a Pós-Orogênicos do Ciclo Brasiliano no Cinturão Dom Feliciano-RS. In: S.B.G., Cong. Bras. Geol., 38, Camboriú, Boletim de Resumos Expandidos, 1: 150-152.

Frantz, J.C.; Lima, E. F.; Pinheiro-Machado, R.; Naumann, M.P. 1984. Contribuição à geologia da região de Encruzilhada do Sul, RS. In: S.B.G., Cong. Bras. Geol., 33, Rio de Janeiro, Anais, 5: 2407-2416.

Frantz, J.C. e Nardi, L. V.S. 1992a. O Magmatismo Granítico da Região Oriental do Escudo Sul-rio-grandense. Uma Revisão. Pesquisas, 19(2): 183-189.

Frantz, J.C. e Nardi, L. V.S. 1992b. Litoquímica e Evolução de Granitóides Cálcio-alcalinos da Região Leste do Escudo Sul-rio-grandense. Pesquisas, 19(1): 13-25.

Frantz, J.C. e Remus, M.V.D. 1986. Geologia da Região de Canguçu-Torrinhas, RS-Caracterização Petrográfica, Estrutural e Estratigráfica. In: S.B.G., Cong. Bras. Geol., 34, Goiânia, Anais, 2: 931-948.

Hasui, Y.; Carneiro, C.D.R.; Coimbra, A.M. 1975. The Ribeira Fold Belt. Rev. Bras. Geoc., 5(4): $257-256$.
Innocent, C; Briqueu, L; Cabanis, B. 1994. Sr-Nd isotope and trace-element geochemistry of late Variscan volcanism in the Pyrenees: magmatism in post-orogenic extension? Tectonophysics, 238: 161-181.

Issler, R.S.; Burger Jr, C; Roisenberg, A. 1967. Coronito da área de Mata Grande, Município de São Sepé, Estado do Rio Grande do Sul. In: S.B.G., Cong. Bras. Geol., 21, Curitiba, Anais, 1: 182-197.

Jacobshagen, V. 1994. Orogenic evolution of the Hellenides: new aspects. Geol. Rundsch., 83(2): 249-256.

lost, H. 1981. Geology and metallogeny of the Santana da Boa Vista Region, Southern Brazil. University of Georgia, Athens, Tese de Doutorado, 208p.

Jost, H.; Frantz, J.C.; Brod, J.A. 1984. Revisão da Tipologia, Cronologia e Significado Geotectônico dos Falhamentos do Escudo Sul-rio-grandense. In: S.B.G., Cong. Bras. Geol., 33, Rio de Janeiro, Anais, 3: 1707-1720.

Koester, E.; Kraemer, G.; Tommasi, A.; Soliani Jr., E.; Fernandes, L.A.D. 1994. Evolução Geocronológica do Magmatismo Sintectônico à Zona de Cisalhamento Dorsal de Canguçu (RS): Dados Rb/Sr. In: S.B.G., Cong. Bras. Geol., 38, Camboriu, Boletim de Resumos Expandidos, 2: 383-384.

Moreno-Ventas, I; Rogers, G.; Castro, A. 1995. The role of hybridization in the genesis of Hercynian granitoids in the Credos Massif, Spain: inferences from Sr-Nd isotopes. Contrib. Mineral. Petrol., 120: 137-149.

Nardi, L.V.S. e Hartmann, L.A. 1979. O Complexo Granulítico Santa Maria Chico, RS. Estudos Tecnológicos, v. III. Acta Geol. Leopold., 6: 45-75.

Saunders, A.D.; Norry, M.J.; Tarney, J. 1991. Fluid influence on the trace element compositions of subduction zone magmas. Phil. Trans. R. Soc. Land. A, 335(1638): 377-392.

Serri, G.; Innocenti, F; Manetti, P. 1993. Geochemical and petrological evidence of the subduction of delaminated Adriatic continental lithosphere in the genesis of the Neogene-Quaternary magmatism of central Italy. Tectonophysics, 223: 117-147.

Soliani Júnior, E. 1986. Os dados geocronológicos do Escudo Sul-rio-grandense e suas implicações de ordem geotectônica. Inst. de Geociências, Universidade de São Paulo, São Paulo, Tese de Doutorado, 239p. 
Sun, S; Warren, R.G.; Shaw, R.D. 1995. Nd isotope study of granites from the Arunta Inlier, central Australia: constraints on geological models and limitation of the method. Precam. Res., 71: 301-314.

Tommasini, S.; Poli, G.; Halliday, A.N. 1995. The role of sediment subduction and crustal growth in Hercynian plutonism: Isotopic and trace element evidence from the Sardinia-Corsica Batholith. / Petrol., 36(5): 1305-1332.

Turner, S; Arnaud, N; Liu, J.; Rogers, N.; Hawkesworth, C; Harris, N.; Kelley, S.; VanCalsteren, P.; Deng, W. 1996. Post-collision, shoshonitic volcanism on the Tibetan Plateau: Implications for convective thinning of the lithosphere and the source of ocean island basalts. J. Petrol., 37(1): 45-71.
Worku, H. e Schandelmeier, H. 1996. Tectonic evolution of the Neoproterozoic Adola Belt of southern Ethiopia: evidence for a Wilson Cycle process and implications for oblique plate collision. Precambrian Res., 77(3/4): 179-210

Zhao, J. e McCulloch, M.T. 1996. Geochemical and Nd isotopic systematics of granites from the Arunta Inlier, central Australia: implications for Proterozoic crustal evolution. Precam. Res., 71: 265-299.

Manuscrito A-1028 Recebido em 12 de setembro de 1998 Revisão dos autores em 20 de janeiro de 1999 Revisão aceita em 22 de janeiro de 1999 